\title{
HOT-FIRE TESTING OF LIQUID OXYGEN / HYDROGEN SINGLE COAXIAL INJECTOR AT HIGH-PRESSURE CONDITIONS WITH OPTICAL DIAGNOSTICS
}

\author{
D. I. Suslov, J. S. Hardi, B. Knapp, and M. Oschwald \\ Institute of Space Propulsion, Germany Aerospace Center (DLR) \\ Lampoldshausen 74219, Germany
}

\begin{abstract}
Injector behavior is of utmost importance for the performance and stability of liquid rocket engines (LREs). A major problem is getting a highly efficient homogeneous mixture and effective chemical reaction of fuels at minimum chamber length. Despite substantial progress in numerical simulations, a need for experimental data at representative conditions for development and validation of numerical design tools still exists. Therefore, in the framework of the DLR-project "ProTau," the authors have performed tests to create an extended data base for numerical tool validation for high-pressure liquid oxygen ( $\mathrm{LOx})$ / hydrogen combustion. During the experimental investigations, a windowed DLR subscale thrust chamber model "C" (designated BKC) has been operated over a broad range of conditions at reduced pressures of approximately $0.8(4 \mathrm{MPa})$, $1(5 \mathrm{MPa})$, and $1.2(6 \mathrm{MPa})$ with respect to the thermodynamic critical pressure of oxygen. Liquid oxygen and gaseous hydrogen $\left(\mathrm{GH}_{2}\right)$ have been injected through a single coaxial injector element at temperatures of $\sim 120$ and $\sim 130 \mathrm{~K}$, respectively. High-speed optical diagnostics have been implemented, including imaging of $\mathrm{OH}^{*}$ emission and shadowgraph imaging at frequencies from 8 up to $10 \mathrm{kHz}$ to visualize the flow field.
\end{abstract}

\section{NOMENCLATURE}

$J \quad$ momentum ratio, $J=\rho_{\mathrm{H}_{2}} v_{\mathrm{H}_{2}}^{2} /\left(\rho_{\mathrm{LOx}} v_{\mathrm{LOx}}^{2}\right)$

LOx liquid oxygen

LRE liquid rocket engine

$P_{\mathrm{CC}}$ combustion chamber pressure

$P_{r} \quad$ reduced pressure, $P_{r}=P_{\mathrm{CC}} / P_{\text {crit } \mathrm{O}_{2}}$

$\mathrm{ROF}$ oxygen to fuel ratio

$\mathrm{VR}$ velocity ratio, $\mathrm{VR}=V_{\mathrm{GH}_{2}} / V_{\mathrm{LOx}}$ 


\section{INTRODUCTION}

In the development of modern LREs, injector head design is of the utmost importance for performance and combustion stability. Optimized designs must show high combustion efficiency in combination with low pressure drop across the injector at minimum chamber length and low manufacturing costs.

Modern LREs operated with LOx and hydrogen like the Space Shuttle Main Engine (SSME), RD-0120, and the Ariane 5 Vulcain II engine are equipped with classical shear-coaxial injector elements. While LOx is fed through the central tube at about $20-30 \mathrm{~m} / \mathrm{s}$, hydrogen is delivered through a circumferential passage at high velocities of about $200-300 \mathrm{~m} / \mathrm{s}$. The atomization and the mixing processes are driven by LOx jet disintegration due to shear forces. Coaxial injectors provide a uniform initial distribution of the LOx and adequate mixing characteristics and show sufficient overall performance and stable operation.

The research activities of the last few years on $\mathrm{LOx} / \mathrm{H}_{2}$ have provided an improved understanding of the injection und combustion processes in LREs. But many thermo- and fluid dynamic effects on highly turbulent, reactive flow fields at elevated pressure remain widely unknown.

Today, the development of new rocket propulsion occurs during an era of significantly reduced research and development budgets. However, the capabilities of computational systems are growing rapidly. Consequently, the main focus in development of new concepts, or upgrades to previous designs, has been shifting more and more from the paradigm of the 1950s-1960s of full-scale hot fire testing to numerical modeling and simulation.

Despite substantial progress in numerical modeling, a need for experimental data at representative conditions for the development and validation of numerical design tools still exists. Thorough validation of numerical models requires not only experimentally determined global parameters such as combustion chamber pressure and mass flow rates, but also highly detailed and precise information concerning the flow parameters as well as impeccable knowledge of the boundary conditions during the test. Realising these requirements often leads to "partial modeling" by reference experiments to investigate selected phenomena and deliberately ignoring some of the similarity requirements depending upon the problem at hand. To help bridge such data sets with reality, windowed combustion chambers with single coaxial injector have sometimes been used for intrachamber injection and combustion studies by providing optical access for the application of optical diagnostics parallel to conventional measurement of global parameters.

One such windowed combustion chamber is the model " $\mathrm{C}$," referred to as BKC, operated at DLR Lampoldshausen. A new test campaign with BKC was performed in the current work, with the aim of generating a comprehensive experimental database for operating conditions representative of industrial rocket combustion chambers, including chamber pressures below, near, and above the 
thermodynamic critical point of oxygen. In contrast to earlier publications presenting BKC results [1-5], this new data set includes detailed measurement of boundary conditions as well as optical diagnostic data over a long distance from the injector head, from 0 up to $370 \mathrm{~mm}$. In this paper, preliminary analysis from this data set which is anticipated will assist in providing a comprehensive quantitative and qualitative basis for validation of numerical models and contribute to the understanding of high pressure combustion phenomena is presented.

\section{EXPERIMENTAL SETUP AND TEST PARAMETERS}

\subsection{Test Bench}

The investigations presented here were performed at the European Research and Technology Test Facility P8 (Fig. 1). The P8 facility is a high-pressure test bench for subscale rocket trust chambers located at the Institute of Space Propulsion at DLR Lampoldshausen.

This test facility enables investigations with the cryogenic propellants hydrogen, oxygen, and natural gas at typical rocket engine operating conditions [6-8]. The supply systems of $\mathrm{P} 8$ are operated in a controlled blowdown mode. The high-pressure propellant supply systems for $\mathrm{H}_{2}$ and LOx are designed for interface pressures at the experimental test specimen of up to 360 bar with mass flow rates from 0.05 to $3.0 \mathrm{~kg} / \mathrm{s}$ for $\mathrm{H}_{2}$, from 0.2 to $7 \mathrm{~kg} / \mathrm{s}$ for liquid natural gas, and from 0.2 to $17 \mathrm{~kg} / \mathrm{s}$ for LOx. The interface temperature for hydrogen is between $30 \mathrm{~K}$ and ambient.

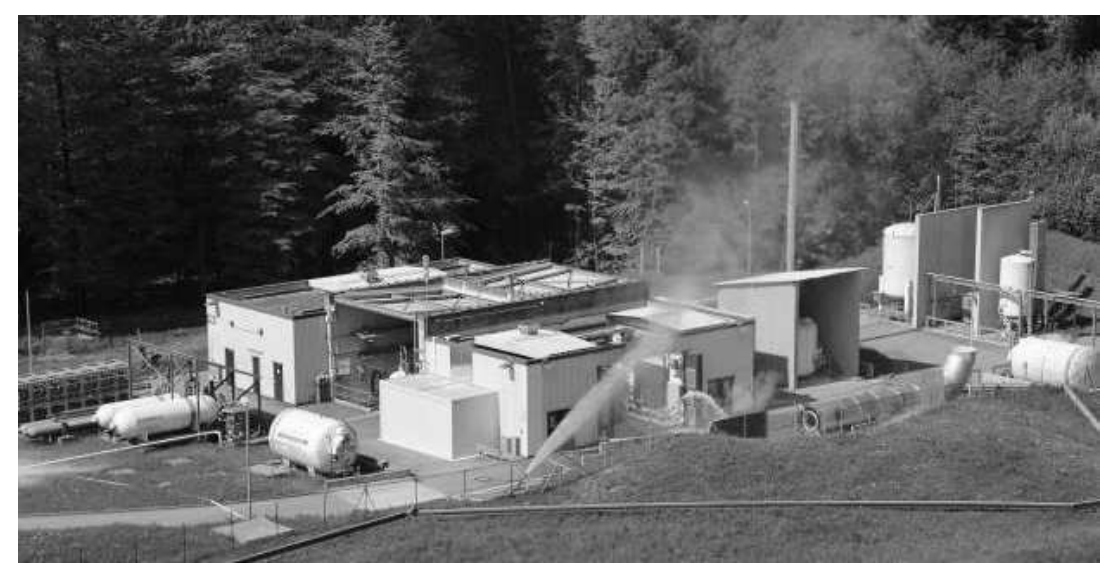

Figure 1 European Research and Technology Test Facility P8, DLR Lampoldshausen 


\subsection{Combustion Chamber}

The windowed combustion chamber has been specifically developed and manufactured for intrachamber injection and combustion studies by providing optical access for the application of optical diagnostics. A sketch of the windowed combustion chamber is given in Fig. 2. The combustion chamber can be operated at up to 7.0 MPa. The chamber is highly versatile with interchangeable nozzles and injector head configurations.

The combustion chamber is segmented into four separate water-cooled sections and a nozzle. On these grounds, the windowed section can be placed at various axial locations. This feature has been used to achieve optical access along the full combustion chamber length, 0 to $370 \mathrm{~mm}$. This distance is close to the length of real rocket engines up to nozzle throat. Figure 3 shows the tested configurations of the combustion chamber and Table 1 presents corresponding position of the optical access.

Quartz glass windows are fitted to the chamber as seen in Fig. 2. The glass windows provide the optical access necessary for the diagnostics. The windows are protected from thermal loads by hydrogen film cooling at ambient temperature. The coolant film is injected through a ring slot located at the outer diameter of the chamber. The $\mathrm{H}_{2}$ cooling film also prevents contact of the combustion products with the window surface and accumulation of condensed water on the inner surface maintaining a clear optical path. To improve the cooling efficiency and reduce the influence of the film on atomization and combustion processes, the film injection velocity has been kept nearly equal to the velocity

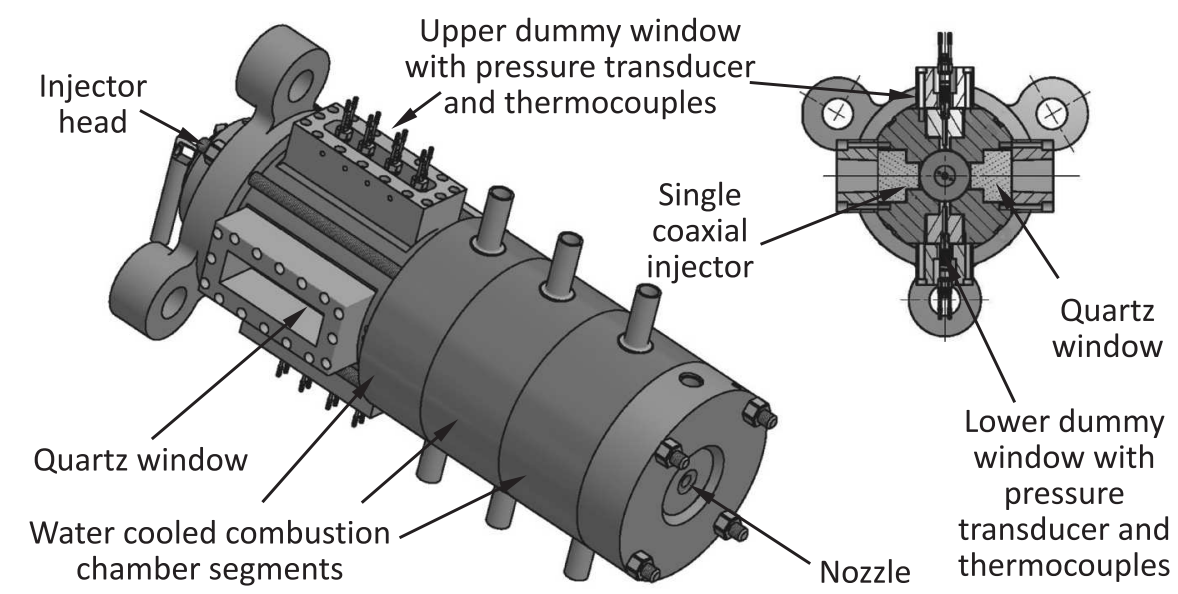

Figure 2 The DLR subscale combustion chamber model "C" (BKC) with optical access 


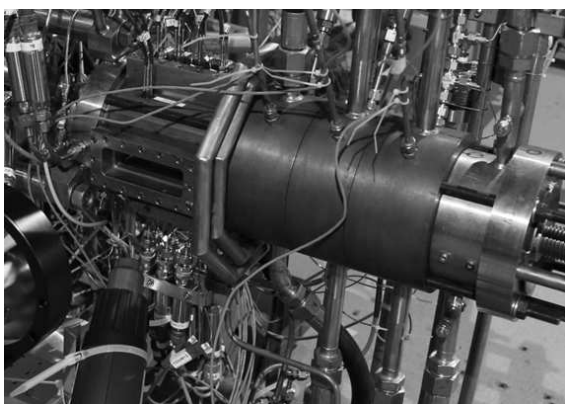

(a)

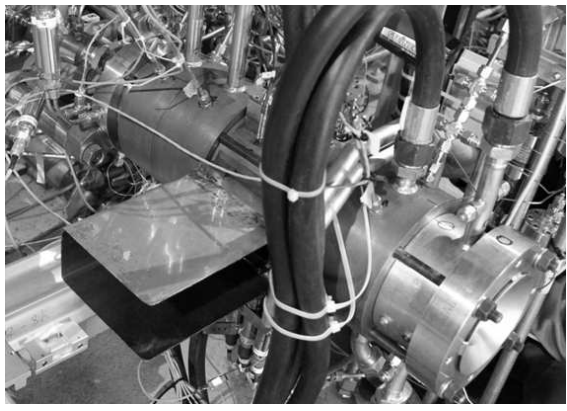

(c)

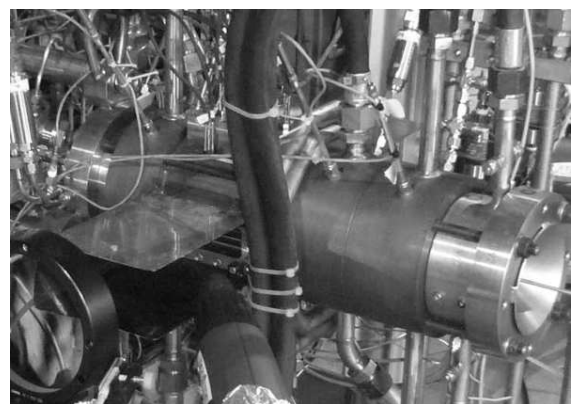

(b)

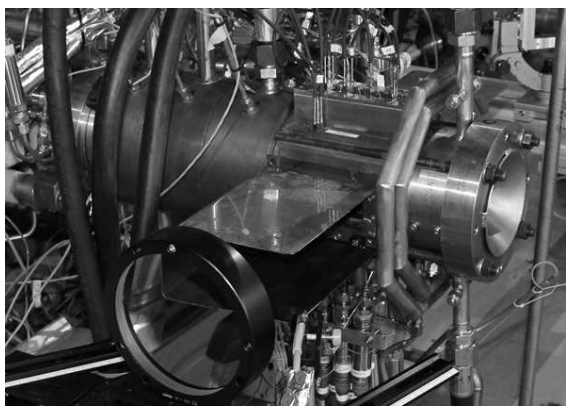

(d)

Figure 3 Tested configurations of the subscale combustion chamber model "C:" $(a)$ to $(d)$ indicate configurations 1 to 4

of the hot gas main flow at all operating conditions. This additionally simulates conditions in a multiinjector combustion chamber with surrounding coflow.

The chamber housing the optical access windows also has dummy windows in the upper and low walls. The dummy windows manufactured from nickel alloy have been used for the measurement of pressure distribution and surface temperature. The nickel-alloy has a similarly low thermal conductivity as the quartz optical access windows approximating an adiabatic boundary condition.
Table 1 Position of the viewed area as a distance from injector head

\begin{tabular}{cc}
\hline Configuration & $\begin{array}{c}\text { Viewed area } \\
\text { as a distance } \\
\text { from injector } \\
\text { head, mm }\end{array}$ \\
\hline 1 & $1-100$ \\
2 & $90-190$ \\
3 & $180-280$ \\
4 & $270-370$ \\
\hline
\end{tabular}

In the centrally positioned primary injector, $\mathrm{LOx}$ is provided as the oxidizer whilst the fuel is $\mathrm{GH}_{2}$. Each propellant is strictly regulated as required and introduced to the combustion chamber via isolated manifolds at the head 


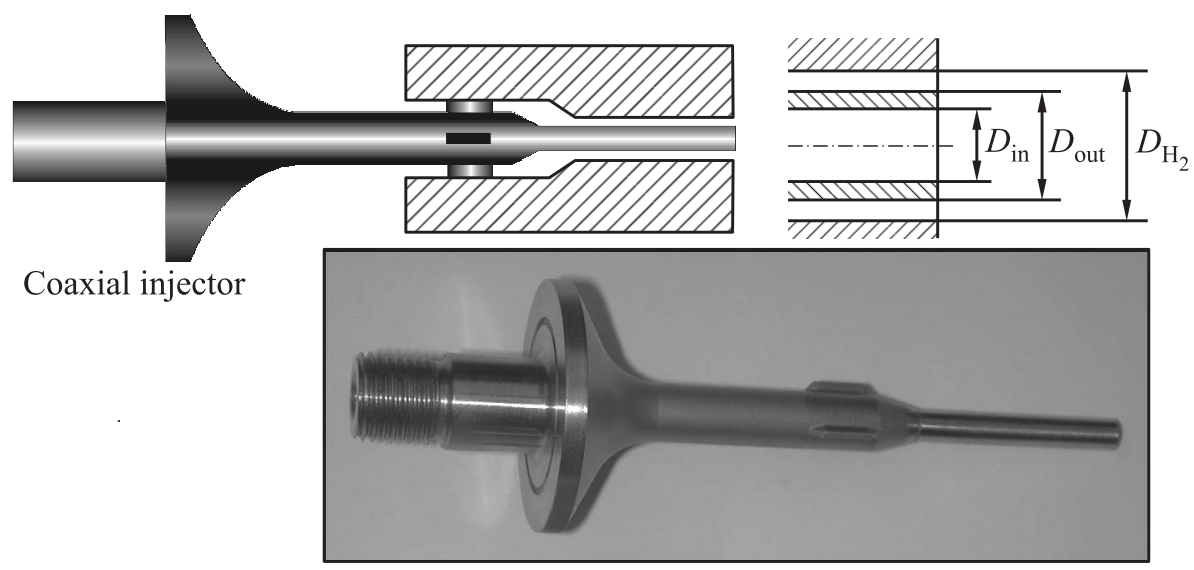

Figure 4 Injector design for subscale combustion chamber model "C:" injector LOx-post; $D_{\text {in }}=4.0 \mathrm{~mm}$; and $D_{\text {out }}=4.6 \mathrm{~mm}$; and $D_{\mathrm{H}_{2}}=6.8 \mathrm{~mm}$

of the chamber. An array of thermocouples is mounted throughout the supply system and propellant manifolds for accurate determination of the injection conditions.

The chamber has an interchangeable injection head that allows an integration of the range of injector types with different geometries. Works presented here are studies utilizing a single shear coaxial injector element without tapering and recess. Figure 4 shows the design and key parameters of the injector element.

\subsection{Test Parameters}

A well-established operating sequence has been used to provide steady-state conditions at three relevant pressure levels including sub-, near-, and supercritical conditions with respect to the critical pressure of oxygen as seen in Fig. 5. In this context, the reduced pressure has been defined as $P_{r}=P_{\mathrm{CC}} / P_{\mathrm{crit} \mathrm{O}_{2}}$. Each pressure level includes three different ROF ranges of 6,5 , and 4 . The duration of each load step is $8 \mathrm{~s}$, which allows a stable, steady-state thermal and flow condition to be reached. The last $1 \mathrm{~s}$ of each test condition (step) has been used for high-speed optical imaging. The high-precision regulation system and extensive experience of the test personnel provided superior repeatability of the test conditions $( \pm 2 \%)$, which is of great importance for a comparison test runs with different hardware configurations.

The injection conditions for all load steps are shown in Table 2. The LOx and $\mathrm{H}_{2}$ injection temperatures have been held relatively constant at 120 and $160 \mathrm{~K}$, 


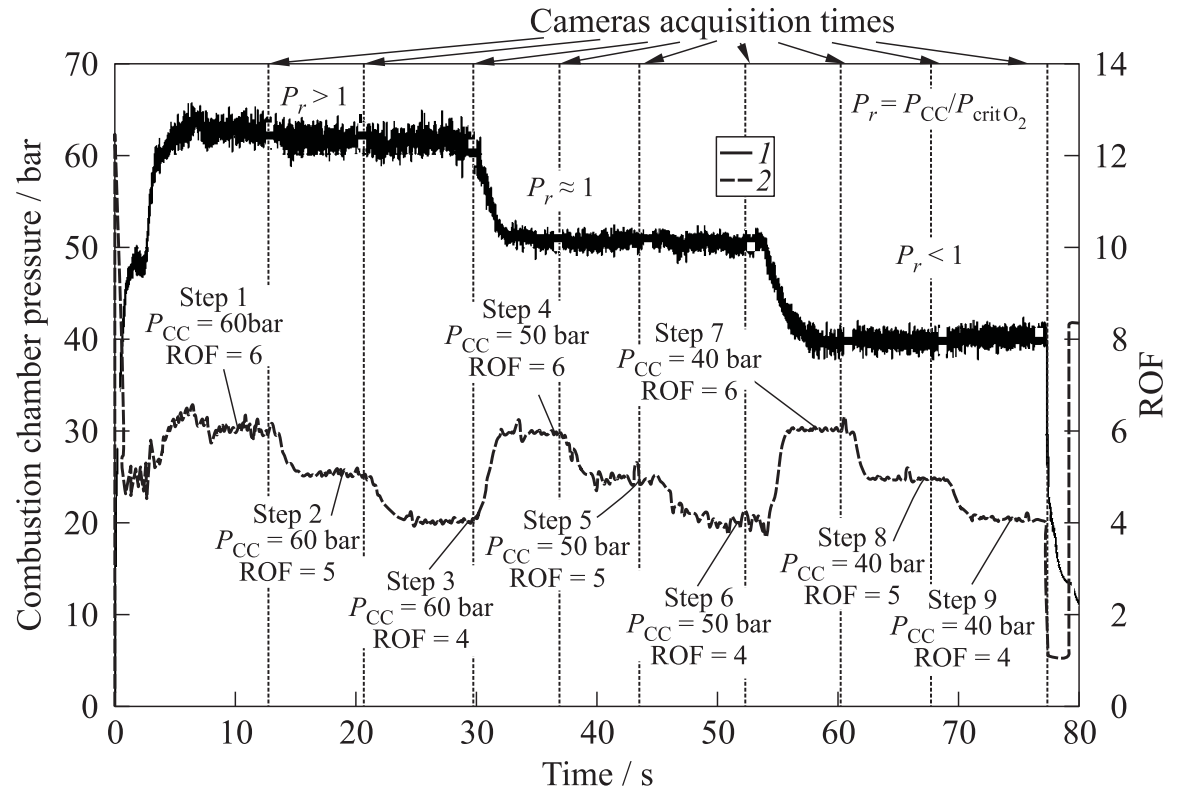

Figure 5 Test sequence: $1-P_{\mathrm{CC}}$ and $2-\mathrm{ROF}$

Table 2 Injection parameters

\begin{tabular}{cccccccccc}
\hline $\begin{array}{c}\text { Load } \\
\text { step }\end{array}$ & $\begin{array}{c}P_{\mathrm{CC}}, \\
\text { bar }\end{array}$ & ROF $_{\text {inj }}$ & ROF $_{\mathrm{CC}}$ & $\begin{array}{c}T_{\text {inj } \mathrm{H}_{2}}, \\
\mathrm{~K}\end{array}$ & $\begin{array}{c}T_{\text {inj LOx }}, \\
\mathrm{K}\end{array}$ & $\begin{array}{c}v_{\text {inj } \mathrm{H}_{2}}, \\
\mathrm{~m} / \mathrm{s}\end{array}$ & $\begin{array}{c}v_{\text {inj LOx }}, \\
\mathrm{m} / \mathrm{s}\end{array}$ & VR & $J$ \\
\hline 1 & 62.2 & 6.2 & 1.40 & 164 & 121 & 350 & 30.0 & 11.6 & 1.20 \\
2 & 61.6 & 5.0 & 1.23 & 155 & 115 & 369 & 25.7 & 14.4 & 1.86 \\
3 & 61.3 & 4.0 & 1.12 & 157 & 115 & 441 & 24.0 & 18.3 & 2.96 \\
4 & 50.6 & 5.2 & 1.24 & 100 & 115 & 349 & 20.7 & 16.8 & 2.05 \\
5 & 50.6 & 4.9 & 1.23 & 159 & 116 & 369 & 20.7 & 17.9 & 2.32 \\
6 & 50.5 & 4.0 & 1.13 & 159 & 117 & 437 & 19.8 & 22.1 & 3.56 \\
7 & 39.9 & 4.9 & 1.22 & 161 & 119 & 363 & 16.4 & 22.1 & 2.87 \\
8 & 40.2 & 4.1 & 1.13 & 160 & 119 & 424 & 16.0 & 26.4 & 4.15 \\
9 & 40.1 & 4.0 & 1.13 & 160 & 120 & 426 & 16.0 & 26.6 & 4.28 \\
\hline
\end{tabular}

respectively. Liquid oxygen injection velocities of about $15-30 \mathrm{~m} / \mathrm{s}$ and hydrogen velocities of about $350-440 \mathrm{~m} / \mathrm{s}$ were of the same order of magnitude as those in comparable shear coaxial injector studies $[2,3]$.

The calculation of the injection velocities is based on the full injection area without consideration of the boundary layer displacement thickness. 


\section{OPTICAL SETUP}

Three different camera systems were used to observe the influence of the propellant injection conditions on the flame behavior. All systems had to be specially protected to prevent potential damage by radiative heat transfer, vibrations, or acoustic loads. A specific imaging setup was implemented to capture simultaneous $\mathrm{OH}$ emission and flow visualization with shadowgraph imaging using high-speed cameras. A schematic of the apparatus and a photograph in the test cell are

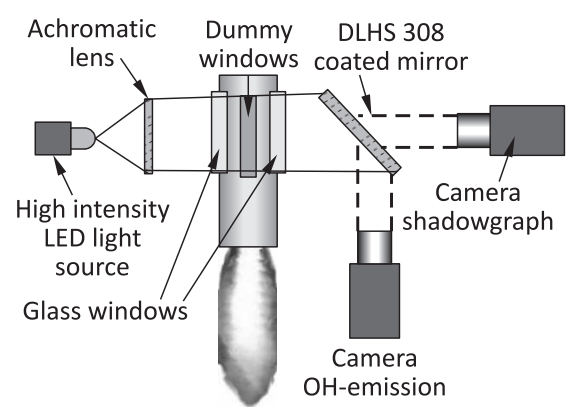

Figure 6 Principal schema of the optical diagnostic setup at the test facility P8 shown in Figs. 6 and 7, respectively.

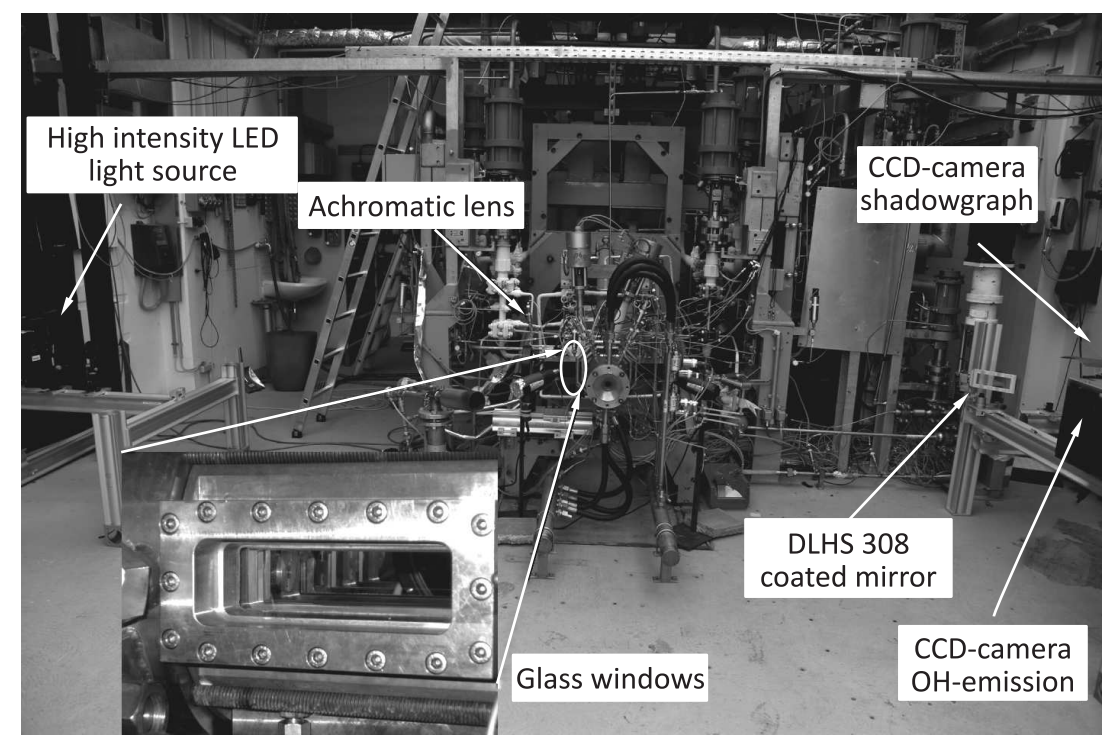

Figure 7 Photograph of the optical diagnostic setup at the test facility P8

\subsection{Shadowgraph System}

The system used for shadowgraph imaging consists of a LED (light-emitting diode) illuminator as a light source, a small aperture followed by an achromatic lens with a focal length of $1250 \mathrm{~mm}$ to perform a parallel light beam through 
the flow field normal to the plane viewing windows of the combustion chamber BKC. At the opposite side of the chamber, a combination of two filters, a 300millimeter camera lens, and a field aperture to reduce scattered light from the environment are located in front of the high-speed camera at a distance behind the combustion chamber. The point shaped light source produces diverging light which is parallelized by the achromatic lens and is then transmitted through the combustion chamber windows. The camera lens focusses the parallel light back to the camera chip and the shadow picture produced by the inhomogeneous density field can now be recorded in the vertical plane of the camera chip placed.

The camera for acquisition of the shadowgraph images with a depth of 8 bit is a Photron Fastcam SA5. Inside the camera, 16 GB RAM can be filled with images that means 10,913 frames at a maximum resolution of $1024 \times 1024$ pixel. Alternatively, 10.000 fps with $512 \times 512$ pixel resolution have been recorded with shutter times between 10 and $20 \mathrm{~s}$. The data transfer from the camera controller to the personal computer was realized via a fiber optic cable. For background illumination, a high-power-LED illuminator model IL-106G was used. This LED illuminator provides extremely bright and noncoherent continuous light with a central wavelength of around $528 \mathrm{~nm}$. This LED lamp was used to get a very high intensity which is much higher than the intensity of the flame, i. e., combustion. In front of the SA5 camera lens, a yellow GG495 filter and a blue BG38 filter have been applied. Both filter characteristics together worked as a band pass filter which passes only the light in the 528-nanometer wavelength region, i. e., the green LED light of the Illuminator. Only the green light is used for the measurement as shadowgraph background light and other visible combustion light; so, all the other flame emission is suppressed.

\subsection{OH Imaging System}

$\mathrm{OH}$ visualization has been carried out simultaneously with the shadowgraph imaging through a 310-nanometer deflective mirror. In order to look at the same point of interest in the flow field inside the combustion chamber with both visible and $\mathrm{OH}$ cameras, this beam splitter has been mounted in the optical path between shadowgraph camera and combustion chamber window in a 45 degree position as can be seen in Figs. 6 and 8. This deflective mirror is a dichroic mirror with 99 percent reflection between 290 and $330 \mathrm{~nm}$ and an approximately 100 percent transmission outside this wavelength range. Therefore, the $\mathrm{OH}$ camera has been setup $90^{\circ}$ to the shadowgraph camera (see Figs. 6 and 8 ).

The $\mathrm{OH}$ emission line of sight images at $310 \mathrm{~nm}$ have been recorded using a Photron Fastcam APX-I2 with a $1024 \times 1024$ pixel CMOS sensor and 17-micron pixel size. Frame rates between 10000 and 24000 fps depending on the test goal have been adjusted with an electronic shutter of 1 /frame. The image resolution of the 8 -bit depth images was set to $256 \times 128$ pixel. The APX camera is equipped 


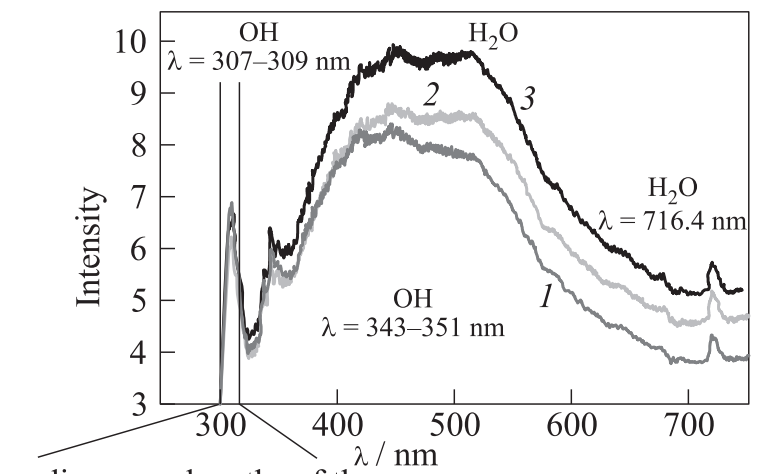

Recording wavelengths of the $\mathrm{CCD}$ camera for $\mathrm{OH}$-emission $301<\lambda<317 \mathrm{~nm}$

Figure 8 Spectrum of $\mathrm{O}_{2} / \mathrm{H}_{2}$ flame at high-pressure combustion: $1-P_{\mathrm{CC}}=40$ bar; $2-50$; and $3-P_{\mathrm{CC}}=60$ bar

with an $\mathrm{OH}$ sensitive F-mount lens with 105-millimeter focal length. In front of the lens, a band-pass filter with a central wavelength of $310 \mathrm{~nm}$ has been used. As already mentioned, data transfer was performed by fire-wire and fibre optic link.

In addition, a backup OH-camera with a low acquisition rate has been mounted with a slight inclined direction to the shadowgraph axis but outside the optical path of the dichroic mirror.

\subsection{Spectroscopic System}

The flame emission signal was focused into a 10-meter long, 600-micron diameter fused silica fiber and delivered to the spectrograph which was positioned in an adjacent diagnostic cell. The spectrograph utilized was a 46-centimeter HR460 (100 grooves/mm) Jobin Yvon. The spectral range was set for 300-700 or 600$1100 \mathrm{~nm}$. This was used in conjunction with a detection system consisting of a back illuminated $600 \times 1752$ CCD detector, an ISI138 16-bit 430-kilohertz controller, and PI Winspec data acquisition software. Spectra acquisition rate was $12,5 \mathrm{~Hz}$ and with a 30 -second test duration.

\section{MEASUREMENT RESULTS}

The focus of the current investigation is to create database for verification of numerical tools. For this purpose, the optical data have been combined with detailed measurement of the surface temperature and pressure distribution along 
the combustion chamber main axis that should serve to define boundary conditions for the numerical simulation.

Measurement points are implemented in upper and lower dummy windows and are shifted together with optical access between configurations. Dummy windows manufactured from nickel alloy have been used for the measurement of the pressure and surface temperature. The nickel-allow has the same low thermal conductivity $(\lambda=15 \mathrm{~W} / \mathrm{mK})$ as quartz-glass. It allows a supposition of adiabatic boundary conditions for the temperature measurements. This also allows significant simplification of the boundary conditions in numerical simulation. Additional pressure measurement points are located in conventional water cooled segments. As a reference value, $x=0 \mathrm{~mm}$ corresponds to pressure that is measured at the face plate of the injector.

\subsection{Temperature and Pressure Distribution}

The pressure evolution along the axis shows a different trend to that typical for multiinjector combustion chambers [8]. Due to a remarkable suction effect from the high velocity film injection, the pressure near the injector head is marginally lower than the middle pressure level. Downstream from the injector head up to position $x=100 \mathrm{~mm}$, the pressure increases and then stays nearly constant in the remaining flow (Fig. 9). Because the change in the pressure level $(2 \%)$ is low in comparison to sensor accuracy, the measurements are also presented as dimensionless specific pressure $\left(P_{\text {rel }}=P_{x} / P_{x=0}\right)$.

The temperature distribution is typical of film cooled surfaces for adiabatic conditions. Surface temperature grows downstream from the film injection plane with decreasing cooling efficiency (Fig. 10). The relative velocity of the cooling film to the hot gas velocity was kept constant by reducing the film mass flow

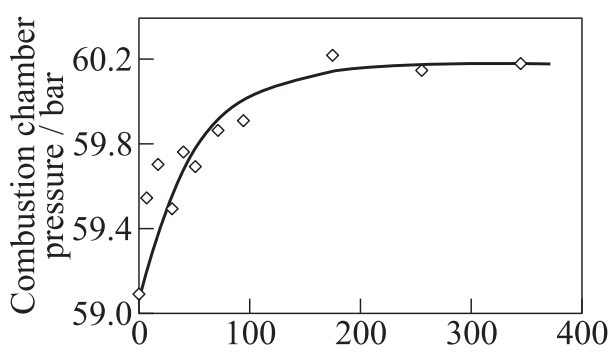

Distance from the injector head / $\mathrm{mm}$

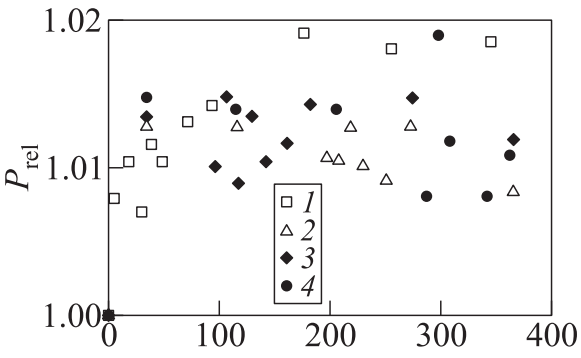

Distance from the injector head / $\mathrm{mm}$

Figure 9 Pressure distribution along combustion chamber main axis: 1 to 4 refer to configurations 1 to 4 


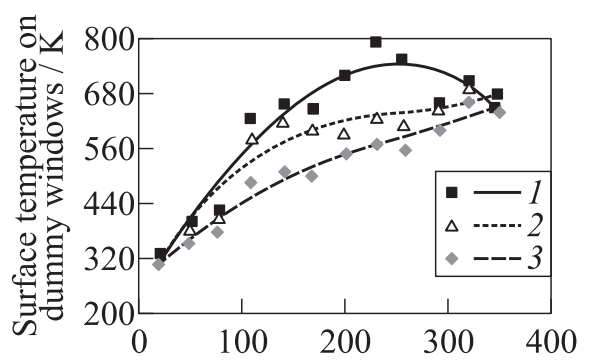

Distance from the injector head / $\mathrm{mm}$

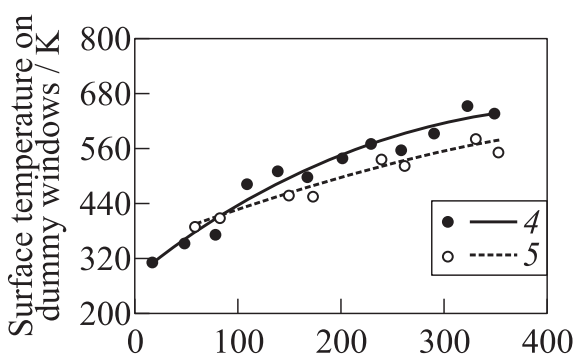

Distance from the injector head / $\mathrm{mm}$

Figure 10 Temperature distribution along combustion chamber main axis: 1 $P_{\mathrm{CC}}=40$ bar; $2-50 ; 3-P_{\mathrm{CC}}=60$ bar; $4-$ upper dummy window; and $5-$ lower dummy window

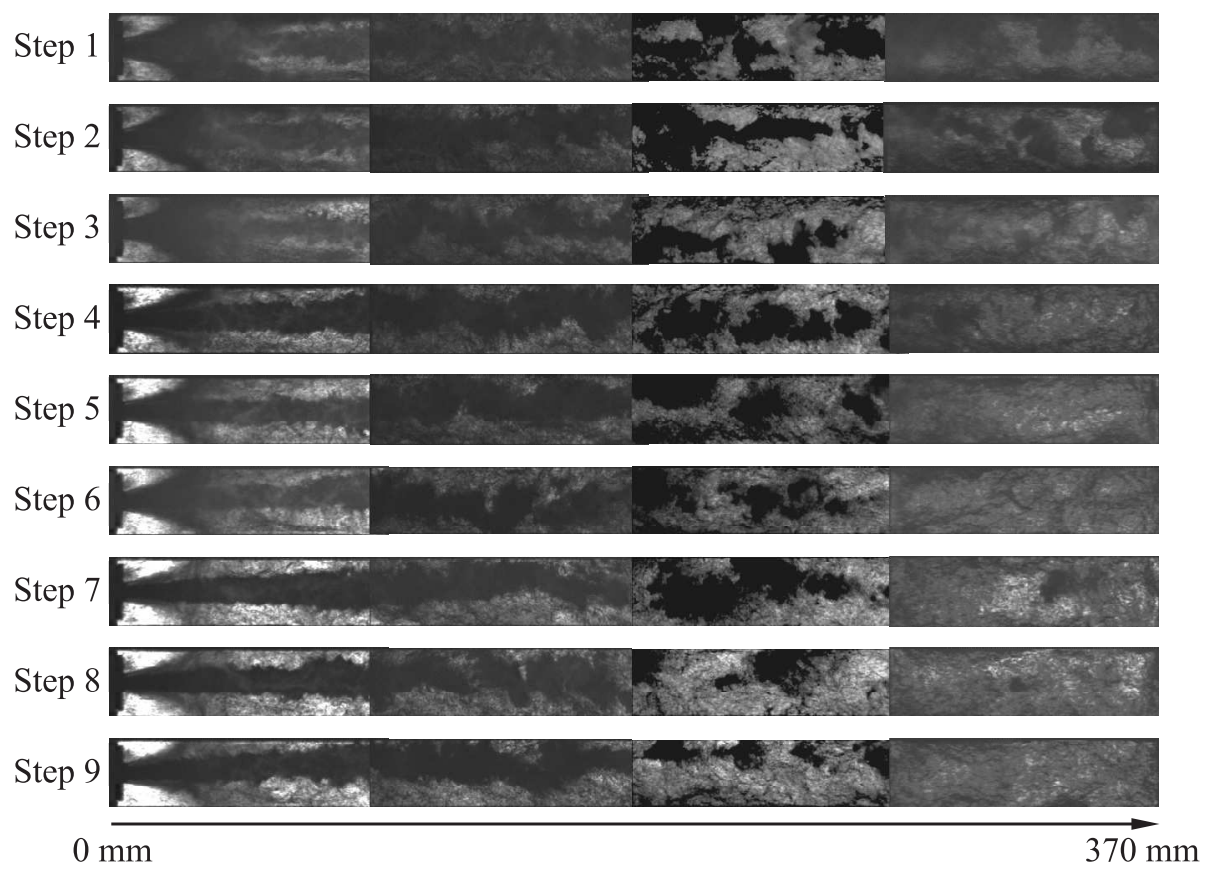

Figure 11 Shadowgraph images at different load steps

with progressing steps in chamber pressure. That leads to increasing of the surface temperature with each decrease in chamber pressure. The injector head is not ideal and has a small asymmetry. This leads to the upper dummy window having a slightly higher surface temperature. It corresponds with optical data (Fig. 11), where LOx-jet deviates slightly upward. 
The influence of the ROF is significantly lower the influence of the pressure and, therefore, is not presented here. Investigations using the optically accessible combustion chamber "C" show only little combustion roughness. The combustion is very stable at all operating conditions, even at subcritical pressures.

\subsection{Optical Investigations}

Figure 11 shows compiled shadowgraph images over the full combustion chamber length at investigated load steps. While at low combustion chamber pressure $\left(P_{r}<1\right.$, load steps $\left.7-9\right)$ atomization of the LOx-core is completed by $x$ $=280 \mathrm{~mm}$, at higher thermal loads $\left(P_{r}>1\right.$, load steps $\left.1-3\right)$ several dark LOxspots are visible up to the end of the observation area. Because the main aim of the investigation is the creation of an extended data basis for numerical tool validation, the major goal of the test program was to maximize the range flow conditions captured. To reduce configuration change work during the campaign, the contraction ratio of $\mathrm{BKC}$ was constant and different pressure was the result of different propellant mass flow rates. Therefore, a direct comparison of the flow conditions at $P_{r}>1$ and at $P_{r}<1$ has very limited relevance and is not presented in this paper.

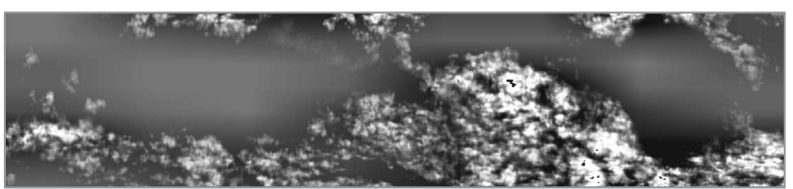

(a)

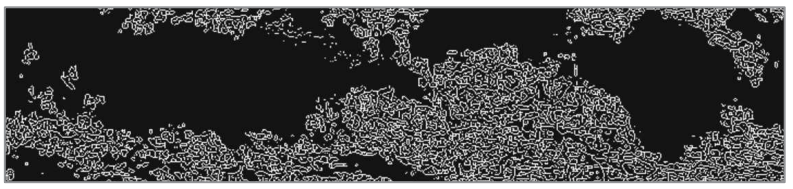

(b)

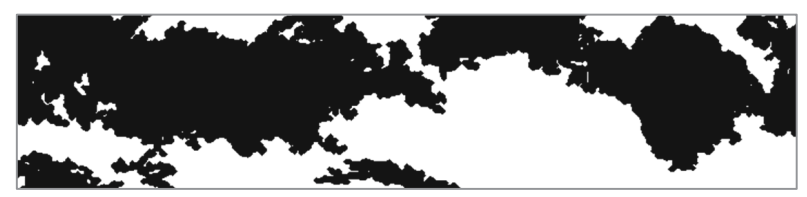

(c)

Figure 12 Processing steps for the shadowgraph analysis: (a) original image; (b) gradient recognition; and $(c)$ shaped LOx-core 


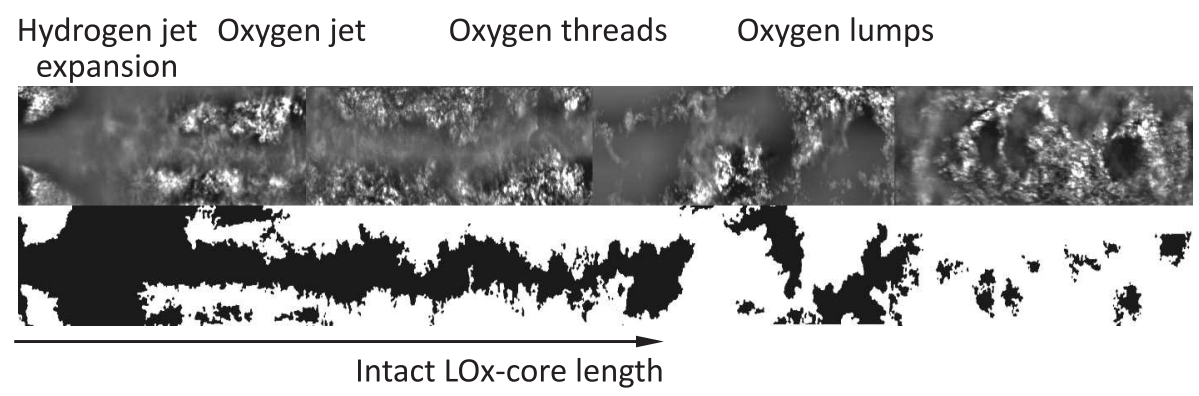

Figure 13 Determination of the intact-LOx core length on the basis of shadowgraph images

Table 3 Intact-LOx core length

\begin{tabular}{ccc}
\hline$P_{\mathrm{CC}}$, bar & ROF & $\begin{array}{c}\text { LOx-core } \\
\text { length, mm }\end{array}$ \\
\hline 60 & 6 & 236 \\
60 & 5 & 218 \\
60 & 4 & 195 \\
50 & 6 & 237 \\
50 & 5 & 210 \\
50 & 4 & 188 \\
40 & 6 & 233 \\
40 & 5 & 203 \\
40 & 4 & 185 \\
\hline
\end{tabular}

The analysis of the LOx-core is hindered by high variation in the absorption coefficient of the dense gas in the combustion chamber, as well as water condensation in the combustion products. To simplify comparison between configurations and operating steps, the shadowgraph images have been converted to the binary (black and white) pictures. The image intensity and texture has been taken into consideration in this process (Fig. 12). This method provides a representation of the shape of the LOx-core with minimal influence from optical effects.

One important parameter is the so-called intact-LOx core length; a length of a completely intact (without interruption) core of LOx. Intact-LOx core length is determined as the distance between the injector face and the first fragmentation of the core region.

Figure 13 shows the processing step to determination intact-LOx core length.

Table 3 and Figs. 14 and 15 present the results as a function of combustion chamber pressure and ROF.

Figure 16 shows compiled $\mathrm{OH}$ images over the full combustion chamber length at investigated load steps. For imaging with configuration 1, at the location 0-100 $\mathrm{mm}$ from the injector face, a higher gain ratio of $\mathrm{OH}$-intensifier has been used to prevent saturation of the emission intensity in the downstream half of the image. It should be taken into account during interpretation of the data. As it is difficult to separate $\mathrm{OH}$ emissivity due to a chemical and a thermal luminescence, these images have not yet been analyzed in more detail. 

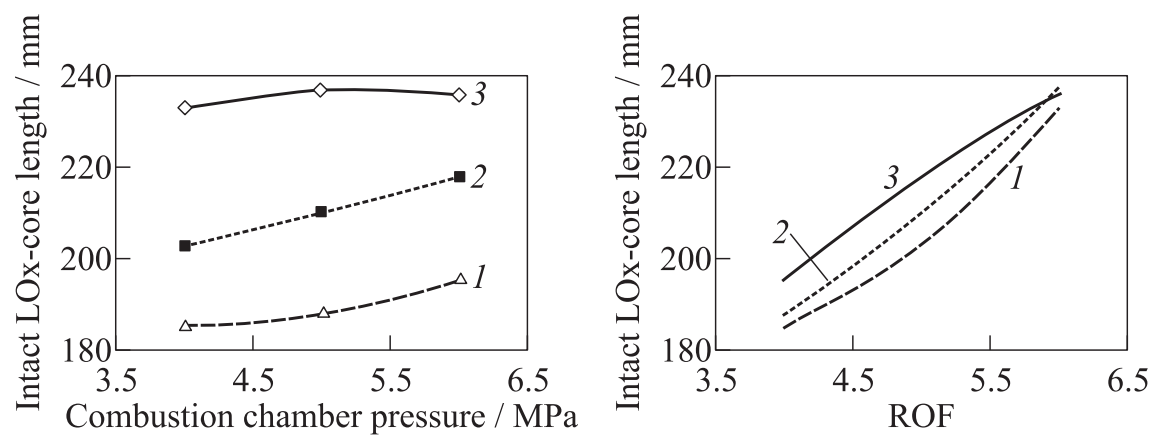

Figure 14 Intact-LOx core length as Figure 15 Intact-LOx core length as a function of combustion chamber pres- a function of ROF: $1-P_{\mathrm{CC}}=4 \mathrm{MPa}$; sure: $1-\mathrm{ROF}=4 ; 2-5$; and $3-2-5$; and $3-P_{\mathrm{CC}}=6 \mathrm{MPa}$ $\mathrm{ROF}=6$

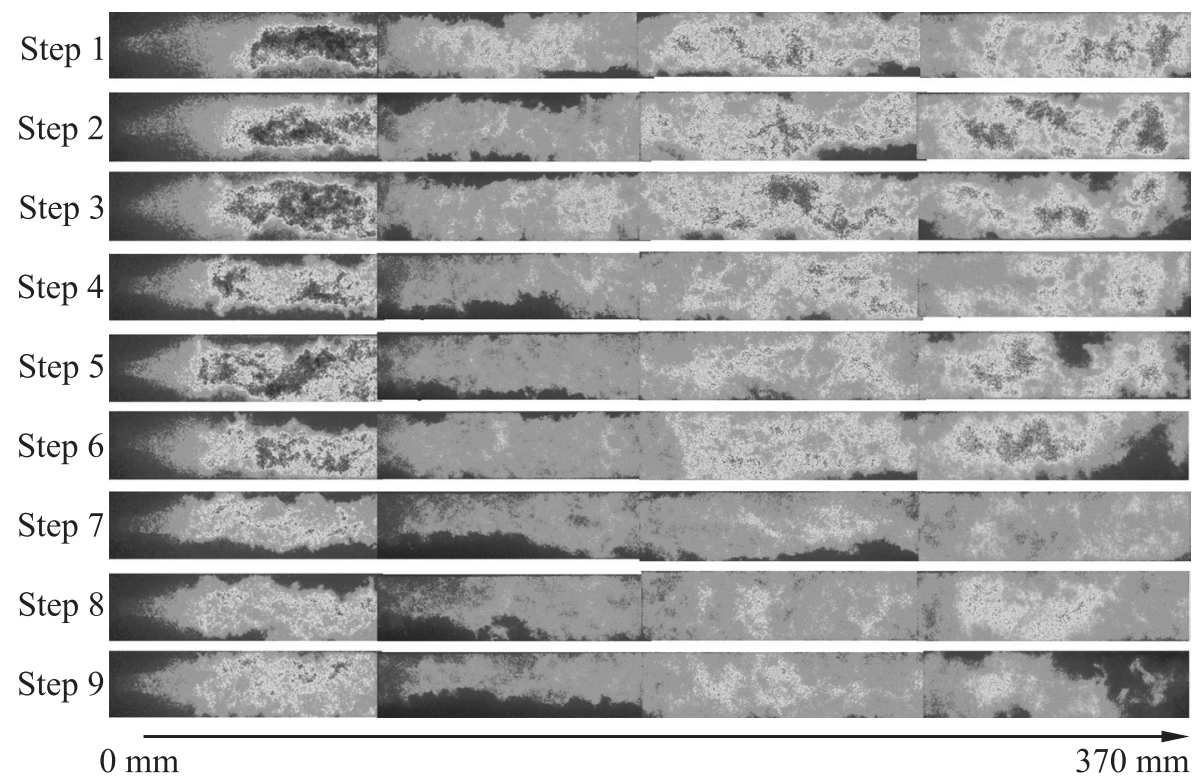

Figure $16 \mathrm{OH}$ images at different load steps

\section{CONCLUDING REMARKS}

Application of high-speed, time-resolved optical diagnostics in combination with conventional measurement techniques has provided quantitative and qualitative 
evidence of dissimilar combustion behavior at various reduced pressure levels through visualization and analysis of flow-field data. Such observations and results highlight the importance of further experimental investigations to provide additional fundamental information and enhance the current understanding of high-pressure, LRE combustion. The data are expected to be of value in the validation of numerical tools for the design of LRE thrust chambers.

\section{ACKNOWLEDGMENTS}

The authors would like to thank the P8 test facility team for their valuable contribution during the test campaign and Fabian Pfähler for his helpful support with data analysis.

\section{REFERENCES}

1. Mayer, W., and H. Tamura. 1996. Propellant injection in a liquid oxygen/gaseous hydrogen rocket engine. J. Propul. Power 12(6):1137-1147.

2. Ivancic, B., and W. Mayer. 2002. Time- and length scales of combustion in liquid rocket thrust chambers. J. Propul. Power 18(2):247-254.

3. Smith, J., G. Schneider, D. Suslov, M. Oschwald, and O. J. Haidn. 2007. Steady state high pressure LOx $/ \mathrm{H}_{2}$ rocket engine combustion. Aerosp. Sci. Technol. 11(1):39-47.

4. Lux, J., D. Suslov, and O. J. Haidn. 2008. On porous liquid propellant rocket engine injectors. Aerosp. Sci. Technol. 12(6):469-477.

5. Locke, J., S. Pal, R. Woodward, and R. Santoro. 2010. High speed visualization of $\mathrm{LOx} / \mathrm{GH}_{2}$ rocket injector flowfield: Hot-fire and cold-flow experiments. 46th AIAA/ASME/SAE/ASEE Joint Propulsion Conference \& Exhibit. Nashville, TN.

6. Haberzettl, A., D. Gundel, K. Bahlmann, M. Oschwald, J. Kretschmer, J.L. Thomas, and P. Vuillermoz. 2000. European research and technology Test Bench P8 for high pressure liquid rocket propellants. AIAA Paper No. 2000-3307.

7. Suslov, D., J. Lux, and O. Haidn. 2007. Investigation of porous injector elements for $\mathrm{LOx} / \mathrm{CH}_{4}$ and $\mathrm{LOx} / \mathrm{H}_{2}$ combustion at sub- and super-critical conditions. 2nd European Conference for Aerospace Sciences.

8. Suslov, D., R. Arnold, and O. J. Haidn. 2009. Investigation of two dimensional thermal loads in the region near the injector head of a high pressure subscale combustion chamber. AIAA Paper No. 2009-450. 